\title{
Analysis of completeness of information in package inserts of Indian and foreign multinational pharmaceutical companies: an Indian perspective
}

\author{
Vikas*, Mahesh Chander Gupta
}

Department of Pharmacology, Pt. BD Sharma PGIMS, Rohtak, Haryana, India

Received: 07 January 2020

Revised: 20 April 2020

Accepted: 22 April 2020

\section{*Correspondence:}

Dr. Vikas,

Email: dr.sehray@gmail.com

Copyright: (C) the author(s), publisher and licensee Medip Academy. This is an open-access article distributed under the terms of the Creative Commons Attribution Non-Commercial License, which permits unrestricted non-commercial use, distribution, and reproduction in any medium, provided the original work is properly cited.

\begin{abstract}
Background: A package insert (PI) should contain all the information required for safe and effective use of the medicine. The present study evaluated and compared the completeness of information in package inserts of Indian and foreign multinational pharmaceutical companies based in India.

Methods: A total 150 PI's consisting of 75 package inserts of Indian and foreign multinational pharmaceutical companies in India were collected and analyzed based on the criteria of Indian drugs and cosmetics rules, 1945 under section 6.2, 6.3 of schedule D, which consists of 25 parameters. Each criteria was scored for presence of information as ' 1 ', absence as ' 0 '. Total score was 25 , score $>20$ was graded as 'A', 10-20 as 'B' and $<10$ as 'C'. Data was expressed as numbers and percentage.

Results: Total 150 PI evaluated included antimicrobials, antipsychotics etc. Out of all the PIs $26 \%$ belonged to grade A, $70 \%$ belonged to grade B and $4 \%$ belonged to grade C. Lack of information was found in both the categories of PIs. Foreign PIs performed better in comparison to Indian PIs as in grade A, 27 out of 41 PIs were foreign whereas 56 PI's in grade B were Indian and 47 were foreign. Both categories of PI showed good information about active ingredient, dosage form, warnings, contraindications and lacked information about retail price and references etc.

Conclusions: Both categories of PIs were deficient in completeness of information. The pharmaceutical companies, both national and foreign, must provide the information as per regulatory norms.
\end{abstract}

Keywords: Package insert, Schedule D, Regulatory

\section{INTRODUCTION}

Accurate and reliable drug information is essential for safe and effective use of marketed products. In developing country like India where about $72 \%$ of the health care burden is borne by the patient and physician gets limited time to explain the drug peculiarities to patient, the role of package insert information becomes significant. ${ }^{1}$ Package insert (PI) is a document provided along with drug in its manufactured container. It is primary source of drug information to any patient containing details of drugs pharmacokinetics and pharmacodynamics properties, its adverse effects, overdose, drug interactions, special warnings and several other instructions. The information presented in the PIs is necessary for both the prescribers and the patients. In Indian scenario, due to inadequate doctor patient ratio, the accessibility to trained prescribers is difficult and physicians are not able to spend enough time with their patients. This gives rise to self-medication, medication errors, and adverse drug reactions. All these issues indicate the need for patient-oriented PIs. The United 
States Pharmacopeia (USP) Medication Errors Reporting Program (MER) found 30\% of the medication errors reported were due to wrong labelling of the medicine. ${ }^{2} \mathrm{~A}$ good PI contains all the approved, essential, and accurate information required for safe and effective use of marketed products. Various studies have concluded that PIs can produce an important impact on patient's compliance and thus on the ultimate effectiveness of drug use. Sholomo et al observed that $51 \%$ of patients reading package inserts developed anxiety and 10\% patients decreased the adherence to treatment. ${ }^{3}$ A survey based study done by Kafeel et al analyzed that $75.6 \%$ responders believed that reading package inserts affect health outcomes. ${ }^{4}$ It is written in a non-promotional, nonmisleading and easy to understand language. In India, the standards of package insert are formalized by the 'drugs and cosmetics act (1940) and rules (1945). The section 6.2 of schedule D (II) of the rules lists the headings according to which information should be provided in the PIs. The 'section 6.3' mandates pharmaceutical information on list of excipients.

In spite of all the regulations, enforcing authorities, quite often these drug package inserts are found to have missing information about various parameters. Mahatme et al, conducted a study to evaluate the adherence of drug package inserts to the recommended guidelines and found the information provided in most of PI's was not uniform and could not be accessed easily. They also noted that government supply inserts are of poorer information than that of non-government package inserts. ${ }^{5}$ Shivkar et al noted, after studying 92 inserts, that most package inserts contained information related to undesirable effects but none of the inserts highlighted the serious adverse events, including ones that could be life-threatening or fatal. ${ }^{6}$

The information on PIs is updated time to time based upon the latest research data. In 2006, US food and drug administration have revised the guidelines for prescription drug information. To manage the risks of medication, use and to reduce medication error, these package inserts were made to provide up-to-date information in easy-to-read format. ${ }^{7}$ A regular audit of package inserts is necessary by the government and the local agencies to ensure that the pharmaceutical companies comply with the regulatory guidelines.

The present study was carried out to critically assess the completeness of information provided in the package inserts of the Indian and foreign multinational pharmaceutical companies in India according to the standards laid down by Indian drugs and cosmetics rules, 1945.

\section{METHODS}

\section{Study design}

This was a survey based observational study conducted by the Department of Pharmacology, Pt. B.D. Sharma
PGIMS, Rohtak (Haryana) from September to October 2019.

\section{Methods}

A total of 150 PIs belonging to different pharmacological classes and formulations were randomly collected from local and regional pharmacy stores, which included 75 package inserts each of Indian and foreign multinational pharmaceutical companies in India. An analysis of the contents of PI's were based on the criteria laid down by Indian drug and cosmetic rules, 1945 under section 6.2, 6.3 of schedule D (II), which consists of 25 parameters (Table 1) recommended for every package insert of drug.

\section{Criteria of package inserts}

The PIs were analyzed based on the following criteria: legibility, approved generic name of active ingredients, content of active ingredient per dosage form, generic names of other ingredients, therapeutic indications, posology and method of administration, contraindications, special warnings and precautions, drug interactions, pregnancy and lactation, pediatric and geriatric indications, special conditions and contraindications, effect on ability to drive and use machines, undesirable effects, drug dose, over dosage, pharmacokinetic information, storage information, instructions for use and handling, shelf life, date on which information was last updated, name and address of manufacturer/distributor, provision of full information on request should be highlighted, retail price of the drug, and references.

\section{Scoring and grading of PI's}

A total score of 25 was assigned to each PI, based on 25 parameters. Presence of parameter on PI was awarded a score of ' 1 ' and absence was awarded ' 0 '. Total score out of 25 was expressed in numbers and percentages.

The scores of package inserts, was classified into 3 grades for the completeness of information based upon the score out of 25. The classification based upon scores was as follows: grade A: score 21-25, grade B: score 1120, and grade C: score 1-10.

The higher grade i.e. grade A, is representative of better completeness of information in PI while grade $\mathrm{C}$ with lower score represent grossly incomplete information provided in PI. ${ }^{11,13}$

Apart from dividing the PIs into grades based upon the scores out of 25 , they were also analyzed and compared for distribution of achieved score.

Percentage value for each item to calculate completeness of information was categorized accordingly - very good: 100-96\%, good: $91-95 \%$, fair: $75-90 \%$, average: $50-74 \%$, and poor: $\leq 50 \%$. 
Apart from dividing the PIs into grades based upon the scores out of 25 , they were also analyzed and compared for distribution of achieved score. All the data was recorded, entered and analysed by a master chart prepared using microsoft excel 2013.

\section{RESULTS}

Total of 164 drug package inserts were collected and 14 were excluded due to duplication. The remaining PI's consisted of 75 each from Indian and foreign multinational companies. Among 150 PI's included in the study, there were 66 tablets, 26 capsules, 22 injections, 14 topicals, 6 eye drops, 2 nasal spray, 5 inhalational drugs and 9 syrups (Figure 1).

The package inserts belonged to various pharmacological classes of drugs (Figure 2). The most frequent classes being antimicrobials, analgesics and antipsychotics whereas PIs of drugs acting on gastrointestinal, skin and endocrinal disorders contributed to lesser extent.

According to section 6.2 the package inserts should be in English and it was found that all the inserts examined were in English and not in regional languages. The presentation of information was not uniform and it was difficult to locate and retrieve the information easily due to lack of common layout and heading.

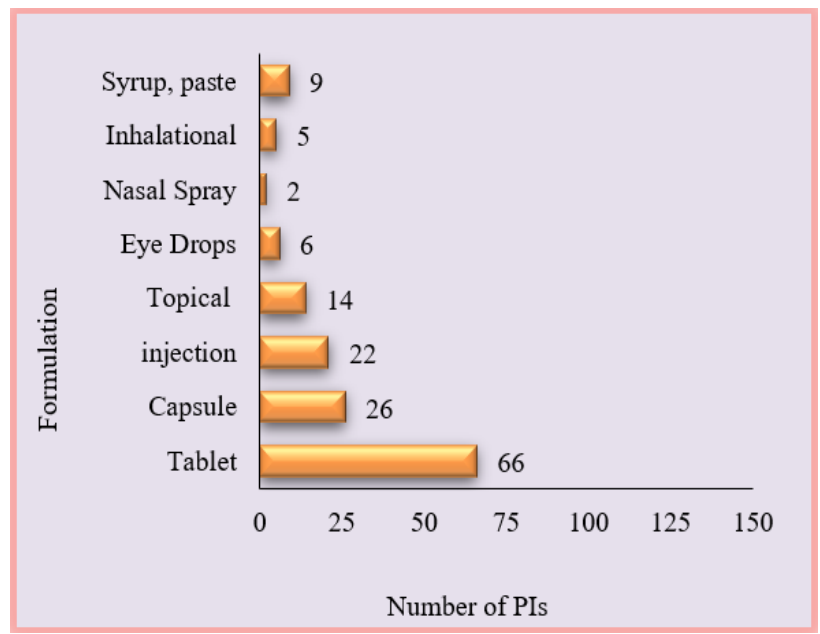

Figure 1: Types and number of formulations of the medicine analyzed for the PIs.

Table 1: Parameters recommended for package inserts in Indian drugs and cosmetics rules 1945 under section 6.2, 6.3 of schedule D (II).

\begin{tabular}{|c|c|c|c|}
\hline S. no. & Parameters & $\%$ Foreign PIs $(\mathrm{n}=75)$ & \% Indian PIs $(\mathrm{n}=\mathbf{7 5})$ \\
\hline 1 & Legibility & 100 & 100 \\
\hline 2 & Approved generic name of active ingredient & 100 & 100 \\
\hline 3 & Content of active ingredient per dosage form & 100 & 100 \\
\hline 4 & Generic names of other ingredients & 97 & 78 \\
\hline 5 & Therapeutic indications & 98 & 92 \\
\hline 6 & Posology and method of administration & 100 & 88 \\
\hline 7 & Contraindications & 96 & 94 \\
\hline 8 & Special warnings and precautions & 98 & 94 \\
\hline 9 & Drug interactions & 96 & 75 \\
\hline 10 & Pregnancy and lactation & 96 & 75 \\
\hline 11 & Pediatrics and geriatric indications & 96 & 75 \\
\hline 12 & Special conditions and contraindications & 97 & 88 \\
\hline 13 & Effect on ability to drive and use machines & 37 & 20 \\
\hline 14 & Undesirable effects & 98 & 97 \\
\hline 15 & Drug dose & 97 & 92 \\
\hline 16 & Antidote for over dosage & 48 & 37 \\
\hline 17 & Pharmacokinetic information & 94 & 93 \\
\hline 18 & Storage information & 96 & 90 \\
\hline 19 & Instructions for use and handling & 100 & 89 \\
\hline 20 & Shelf life & 41 & 41 \\
\hline 21 & Date on which information was last updated & 17 & 12 \\
\hline 22 & Name and address of manufacturer/distributor & 81 & 76 \\
\hline 23 & $\begin{array}{l}\text { Provision of full information on request should be } \\
\text { highlighted }\end{array}$ & 13 & 13 \\
\hline 24 & Retail price of the drug & 8 & 10 \\
\hline 25 & References & 26 & 20 \\
\hline
\end{tabular}


Table 2: Comparison of parameters of completeness of information of Indian and foreign PIs.

\begin{tabular}{|c|c|c|}
\hline Category & Parameters of foreign PIs & Parameters of Indian PIs \\
\hline \multirow{16}{*}{ Very good } & Legibility & \\
\hline & $\begin{array}{l}\text { Approved generic name of active } \\
\text { ingredient }\end{array}$ & \\
\hline & Content of active ingredient per dosage form & \\
\hline & Generic names of other ingredients & \\
\hline & Therapeutic indications & Legibility \\
\hline & Special conditions and contraindications & Approved generic name of active ingredient \\
\hline & Posology and method of administration & Content of active ingredient per dosage form \\
\hline & Contraindications & Undesirable effects \\
\hline & Special warnings and precautions & \\
\hline & Drug interactions & \\
\hline & Pregnancy and lactation & \\
\hline & Pediatrics and geriatric indications & \\
\hline & Undesirable effects & \\
\hline & Drug dose & \\
\hline & Storage information & \\
\hline & Instructions for use and handling & \\
\hline \multirow{5}{*}{ Good } & \multirow{5}{*}{ Pharmacokinetic information } & Therapeutic indications \\
\hline & & Contraindications \\
\hline & & Special warnings and precautions \\
\hline & & Drug dose \\
\hline & & Pharmacokinetic information \\
\hline \multirow{9}{*}{ Fair } & \multirow{9}{*}{ Name and address of manufacturer/distributor } & Generic names of other ingredients \\
\hline & & Posology and method of administration \\
\hline & & Drug interactions \\
\hline & & Pregnancy and lactation \\
\hline & & Pediatrics and geriatric indications \\
\hline & & Special conditions and contraindications \\
\hline & & Storage information \\
\hline & & Instructions for use and handling \\
\hline & & $\begin{array}{l}\text { Name and address of } \\
\text { manufacturer/distributor }\end{array}$ \\
\hline \multirow{7}{*}{ Poor } & Effect on ability to drive and use machines & Effect on ability to drive and use machines \\
\hline & Antidote for over dosage & Antidote for over dosage \\
\hline & Shelf life & Shelf life \\
\hline & Date on which information was last updated & Date on which information was last updated \\
\hline & $\begin{array}{l}\text { Provision of full information on request should be } \\
\text { highlighted }\end{array}$ & $\begin{array}{l}\text { Provision of full information on request } \\
\text { should be highlighted }\end{array}$ \\
\hline & Retail price of the drug & Retail price of the drug \\
\hline & References & References \\
\hline
\end{tabular}

Moreover, the package inserts were of different shapes and sizes with different font size which made it inconvenient for analyzing (Table 1).

The highest score achieved by any package insert was 24 out of 25 and lowest was 9 . Based on their scores out of 25, PI's were divided into A, B and C grades. Out of 150 , $41(27 \%)$ belonged to grade 'A', $103(69 \%)$ belonged to grade B and remaining $6(4 \%)$ belonged to grade ' $\mathrm{C}$ '. The foreign PIs performed better in grade A. 27 out of 41 PIs in grade A belonged to foreign MNCs whereas 56 PI's in grade $\mathrm{B}$ were Indian and 47 were foreign PI's. The grading and score distribution of PIs from Indian and foreign companies is shown in (Figure 3 and 4).

A comparison was made between completeness of each item in both the categories of PI. The completeness was further classified ranging from very good to poor availability of information (Table 2).

Both categories of PIs show very good information about legibility, approved generic name of active ingredient, content of active ingredient per dosage form, undesirable effects and poor information about retail price, date on 
which information was last updated, references and provision of full information on request. In a general comparison between two categories it was found that foreign PIs performed better in extent of providing the information in very good category whereas both performed equally bad in poor category.

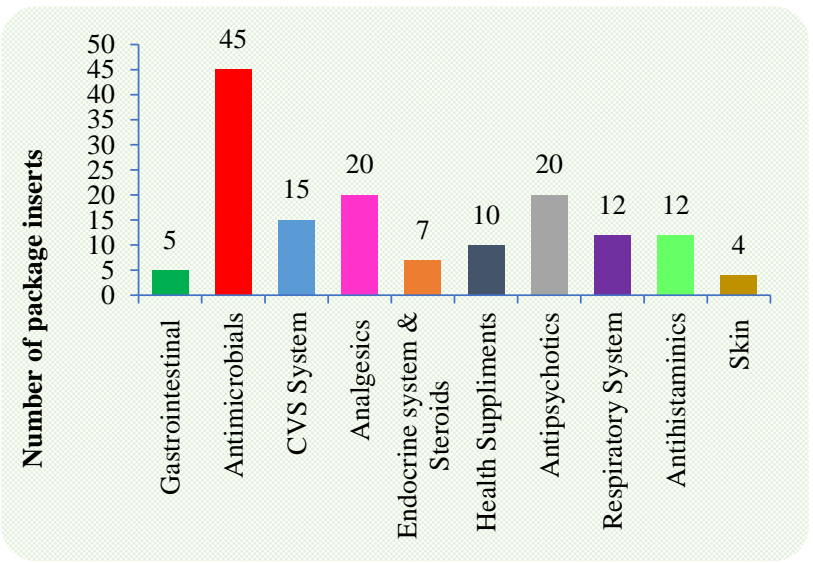

Figure 2: Number and pharmacological classes of the medicines analysed for PIs.

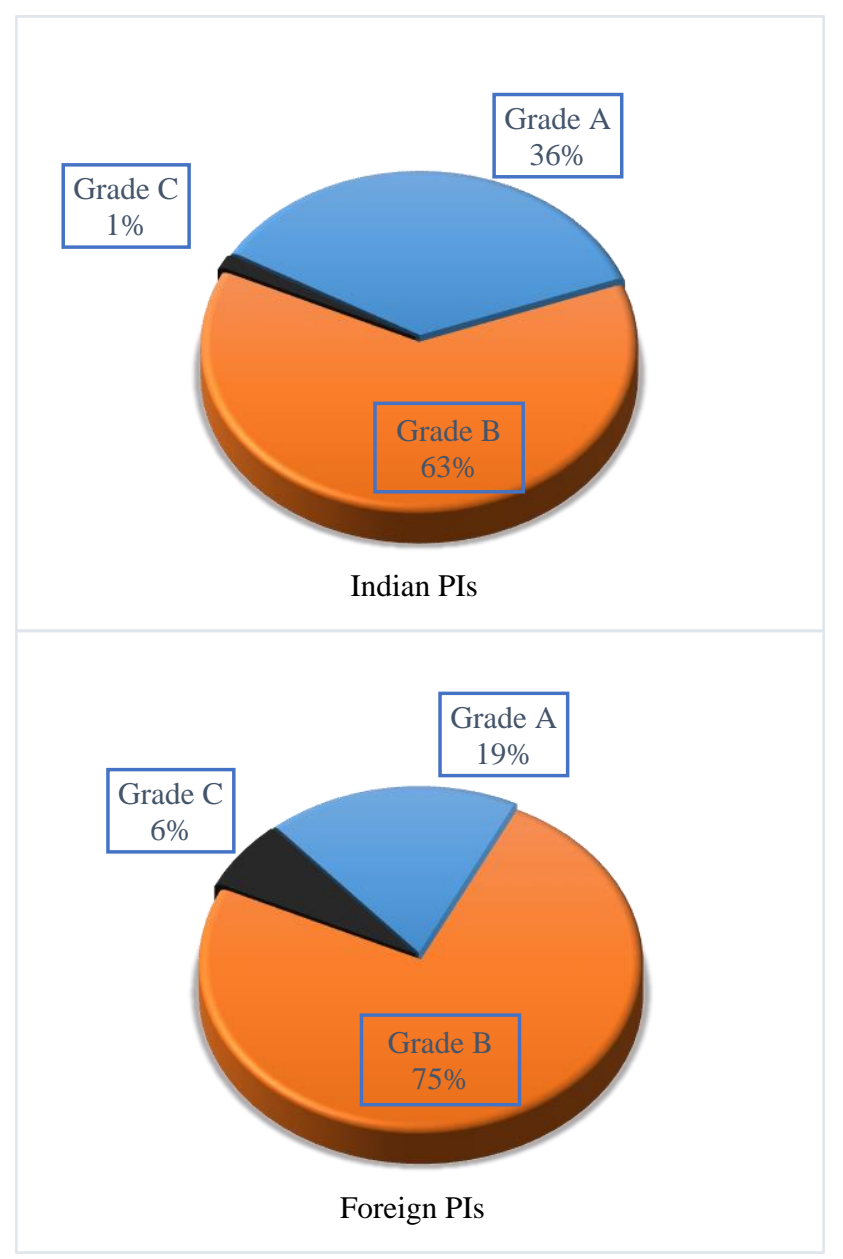

Figure 3: Comparison of grading of completeness of information (percentage) in Indian and foreign PIs.

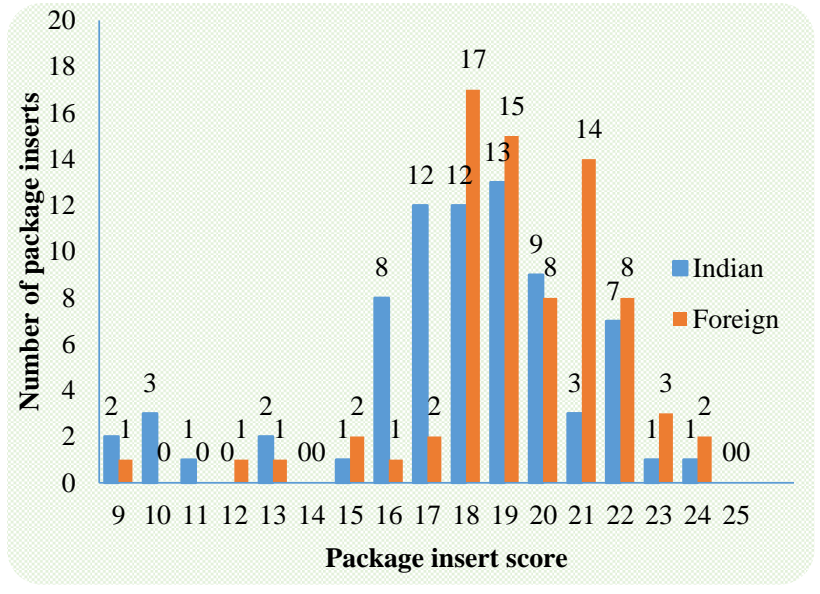

Figure 4: Comparison of scores of PIs achieving score between 9 to 25 as per parameters of the drugs and cosmetics rules 1945.

\section{DISCUSSION}

On analyzing the package inserts, it was found that way of presentation of information varied from one package insert to another. The size and fonts of all the package inserts were not uniform and standardized and this causes inconvenience for reader. A common layout of posology could have made it easier to retrieve information. The variations in layout of PI's is not only in India, studies from abroad have also shown same. Sawalha et al study from Palestine compared local and imported PI's of antiinfective and found that the overall design of PI was different from one local company to another and even between different medications produced by the same company. ${ }^{8}$

The information presented in the PIs is necessary for both the prescribers and the patients. A study assessing private health care providers attitude toward package inserts showed that prescribers consult PI's frequently to know untoward effects and therapeutic indications. $72 \%$ of practitioners found PI's extremely useful. ${ }^{9}$ PIs can help a practitioner only when information in it is well complied with regulatory recommendations. Deficit of information on any parameter can prove consequential. Items in PIs are focused to target physician, pharmacist and patients so all of them can make use of information provided in it. Package inserts have an important impact on patient's compliance and thus on the effectiveness of drug use. Insufficient information in PIs is matter of concern and various studies over the globe have found scarcity of information time to time. A German study conducted to analyze PI's based upon 104 quality criterias showed that in $73.5 \%$ of cases, daily maximum dose was missing, $66.2 \%$ of package inserts provided no instructions about the correct storage. ${ }^{10}$ In present study only $48 \%$ and $37 \%$ Foreign and Indian PI's respectively showed over dosage information. Which has large scope of improvement. The storage information was present in 90 to $96 \%$ of the 
package inserts which is better than above compared study from Germany.

The PI's from Indian and foreign pharmaceutical companies showed poor information particularly about effect of ability to drive and use machine $20 \%$ to $37 \%$, over dosage $37 \%$ to $48 \%$, shelf life (41\%), date on which information was last updated $12 \%$ to $17 \%$, provision for full information on request $(13 \%)$ retail price $8 \%$ to $10 \%$ and references $20 \%$ to $26 \%$. Information on shelf life is important as the drug that has passed its shelf life might still be safe for consumption but its quality cannot be guaranteed. This can lead to poor control of diseases. Also, patients should be well-informed about the retail price of the drugs and should be able to confer to references whenever required. The compromised information about retail price $(3 \%)$, references $(2 \%)$, information update date (12\%) and shelf life (26\%) was also shown previously by Mahajan et al. who analyzed completeness of PIs in Maharashtra. ${ }^{11}$ However, comparing present to previous study of package inserts analysis from Rohtak by Pranjit et al, these parameters have shown improvement. Previous study had assessed lower shelf life (9\%) and ability to drive $(19 \%) .^{12}$

In overall comparison of completeness of Indian and foreign PI's it was found that foreign PI's are providing relatively more information and achieved higher overall scores. The 27 out of 41 PI's in grade 'A' were foreign PI's whereas grade B was dominated by Indian PI's in number. One such comparison between Indian and Foreign PI's was attempted by Ramdas et al in southern India who studied 134 PIs (96 Indian and 38 foreign) and found more number of Indian PI's in grade A. ${ }^{13}$ As a whole nearly $69 \%$ of the package inserts in present study belonged to grade $\mathrm{B}$ which is comparable to above mentioned study who found $76 \%$ of PIs in grade B. Both the studies indicate that Indian as well as foreign PIs are performing poor in providing the information. There are various reasons for not providing complete PI information, one of which is casual attitude of pharmaceutical companies because of laxity in guidelines implementation. Superlative guidelines are indeed necessary but their reinforcement is equally important too. The implementation of guidelines by concerned authorities is as essential as defining the guidelines. Even excellent standard guidelines turn futile without the genuine implementation efforts. Paucity in monitoring of the PIs in post-marketing surveillance by regulatory bodies and lack of robust punishment process empowers pharmaceutical companies to dodge the guidelines. Pharmaceutical companies smartly hide the information which can adversely affect the sales of medicine like adverse effects, contraindications or drug interactions and promote the positive effects of drug like therapeutic indications. It is necessary that PIs must be optimized and tested by selected groups of experts prior to the approval of the drug. This will ensure the avoidance of the lack of information and will guide towards informed and better treatment outcomes.

\section{CONCLUSION}

In this study, it was found that many drugs come with major lacunas in information of package insert. Majority of the PIs were of grade B which suggests relevant information was mentioned but there is sufficient amount of information which was mandatory to mention but was absent from PI's. The Indian PI's need to improve more than foreign PI's.

The current concept of package inserts, which is followed in India, is inadequately serving its purpose of providing satisfactory prescribing guidance in an effective manner. There is a wide variation in the information available on the package inserts of drugs available in the Indian market. A post publishing surveillance to avoid such confusion would be beneficial. A strict watch on such a practice is the need of the hour for the benefit of the patient as well as the society.

\section{ACKNOWLEDGEMENTS}

I sincerely acknowledge the efforts of Dr. Rakesh Mittal for giving me this idea.

Funding: No funding sources

Conflict of interest: None declared

Ethical approval: The study was approved by the Institutional review board

\section{REFERENCES}

1. India New Delhi: Government of India. Ministry of Health and Family welfare: National Health Accounts; 2006.

2. Berman A. Reducing medication errors through naming, labeling, and packaging. J Med Syst. 2004;28(1):9-29.

3. Vinker S, Eliyahu V, Yaphe J. The effect of drug information leaflets on patient behavior. Isr Med Assoc J. 2007;9(5):383-6.

4. Khafeel H. Medication Package inserts, concept among doctors' pharmacists and laypersons-A beneficial guidance or a source of confusion. JMR. 2016;2(3):62-4.

5. Mahatme M, Dakhale G, Hiware S, Wankhede S, Salve A, Mahatme S. Comparison of Indian package inserts in public and private sector: an urgent need for self-regulation. Int $\mathbf{J}$ Basic Clin Pharmacol. 2013;2:165.

6. Shivkar YM. Clinical information in drug package inserts in India. J Postgrad Med. 2009;55(2): 104.

7. Research $\mathrm{C}$ for DE and the FDA Announces New Prescription Drug Information Format FDA $3^{\text {rd }}$ Nov 2018. Available at: http://www.fda.gov/drugs/laws- 
acts-and-rules/fda-announces-new-prescription-druginformation-format. Accessed on 19 December 2019.

8. Sawalha A, Sweileh W, Zyoud S, Jabi S. Comparative Analysis of Patient Package Inserts of Local and Imported Anti-Infective Agents in Palestine. Libyan J Med. 2008;3(4):181-5.

9. Joubert PH, Skene D. Attitudes of private medical practitioners towards package inserts and other drug information sources. South Afr Med J Suid-Afr Tydskr Vir Geneeskd. 1984;66(8):306-7.

10. Fuchs J, Hippius M, Schaefer M. Analysis of German package inserts. Int $\mathbf{J}$ Clin Pharmacol Ther. 2006;44(1):8-13.

11. Manali M, Mahajan, Dudhgaonkar S, Swapnil N, Sachin K, Deshmukh, et al. Analysis of completeness of drug package inserts available in pharmacies of central India. Eur J Pharm Med Res. 2016;3(1):2737.

12. Narzaree P, Gupta MC. A critical appraisal of medication package inserts. IJPR. 2015;5(10):226-30.

13. Ramdas D, Chakraborty A, Faizan S, Kumar VP. A Study of Package Inserts in Southern India. J Clin Diagn Res. 2013;7(11):2475-7.

Cite this article as: Vikas, Gupta MC. Analysis of completeness of information in package inserts of Indian and foreign multinational pharmaceutical companies: an Indian perspective. Int J Basic Clin Pharmacol 2020;9:863-9. 